\title{
La formación humanística de Guillermo Hoyos-Vásquez.
}

The Humanistic Education of Guillermo Hoyos-Vásquez

La formation humaniste de Guillermo Hoyos-Vásquez

A formação humanística de Guillermo Hoyos-Vásquez

Fecha de recepción: 17 DE NOVIEMBRE DE 2013/ Fecha de aceptación: 23 DE ENERO DE 2014

Encuentre este artículo en http://magisinvestigacioneducacion.javeriana.edu.co/ doi:10.11144/Javeriana.M6-13.FHGH

Escrito por Gerardo Remolina-Vargas, S. J.

UNIVERSIDAD JAVERIANA Bogotá, Colombia

gremolin@javeriana.edu.co

Es muy conocida la formación filosófica de GuiIlermo Hoyos-Vásquez: Husserl (su tesis doctoral), la Escuela de Frankfurt (seminarios, cursos y lecturas) y, en especial, Habermas, su pasión de los últimos años. Pero muy pocos conocen el trasfondo humanístico que marcó su actividad filosófica, social y educativa. Guillermo fue un auténtico humanista.

\section{El bachillerato}

Guillermo se formó a la sombra de la educación jesuítica de la mitad del siglo $X X$, entre las décadas del cuarenta y del cincuenta. De niño, estudió en el Colegio San Ignacio, de Medellín y en la Escuela Apostólica de El Mortiño, en Zipaquirá (Cundinamarca). Fue el tiempo correspondiente a los años de primaria y bachillerato. Luego hizo sus primeros estudios en el Colegio Universitario del Sagrado Corazón de Jesús, en Santa Rosa de Viterbo (Boyacá). Los programas educativos que frecuentó estaban marcados, implícita o explícitamente, por las orientaciones de la Ratio Studiorum (u Organización de los Estudios) de la Compañía de Jesús. La Ratio cobijaba todas las instituciones educativas jesuíticas del momento: colegios y universidades. Conocí muy a fondo el sistema de la primera formación de Guillermo porque, pese a la diferencia de dos o tres años que él me llevaba de ventaja, fue el mismo sistema que yo frecuenté.

Cuando éramos niños de 13 o 14 años (cursábamos $3^{\circ}$ y $4^{\circ}$ grado de bachillerato de entonces)

Para citar este artículo / To cite this article / Pour citer cet article / Para citar este artigo Remolina-Vargas, G. (2014). La formación humanística de Guillermo Hoyos-Vásquez. magis, Revista Internacional de Investigación en Educación, 6 (13), 149-152. 
estudiábamos El castellano en los clásicos, una de las obras maestras del filólogo y humanista Félix Restrepo, S. J., fundador del Instituto Caro y Cuervo y después presidente de la Academia Colombiana de la Lengua. La obra recogía trozos selectos de Calderón de la Barca, Lope de Vega, fray Luis de Granada y de otros autores clásicos de la lengua castellana como Andrés Bello, Rubén Darío, Gabriela Mistral, José Santos Chocano, Rafael Pombo, etc. El trabajo de los estudiantes, bajo la guía de los profesores, consistía en leer, apreciar y analizar gramatical y estilísticamente los textos escogidos, aprender los modismos, enriquecer el vocabulario y hacer pequeñas composiciones. El grado siguiente consistía en estudiar la Preceptiva Literaria, con el texto del padre Jesús María Ruano, S. J. Era una obra didáctica que, a partir del análisis de grandes autores, en particular colombianos, nos iba enseñando a gustar de la belleza y la elegancia de su prosa y poesía. Aprendimos de memoria poemas como "La luna", de Diego Fallon; "Las constelaciones", de Rivas Groot; "Los camellos", del maestro Valencia y otras composiciones literarias. Al mismo tiempo, se nos hacía descubrir en ellas la técnica de la composición y ejercitar el estilo en escritos creativos. Había "excursiones literarias", cuyo objetivo era el de aprender a observar y describir la naturaleza. Después de examinar los detalles de un paisaje, de un lago, de una montaña, de un árbol o de una flor, era necesario hacer una composición literaria que reflejara su belleza y el efecto interior que producía su contemplación. Todo invitaba a escribir con soltura, gracia y elegancia, ya fuera en prosa o en poesía.

\section{Los primeros estudios universitarios}

Los autores clásicos latinos

A Guillermo lo encontré por primera vez en Santa Rosa de Viterbo. Allí, el programa de estudios universitarios giraba alrededor de los grandes autores griegos y latinos. Lo primero, desde luego, era aprender a hablar la lengua de Cicerón. Se debía hacerlo con fluidez y propiedad, después de haber superado los tres primeros grados de aprendizaje del latín: Gramática ínfima, media y suprema. En ellos se aprendía morfología, semántica y sintaxis latinas y se redactaban composiciones en esa lengua.

Pero lo más apasionante eran los cursos de Retórica I, II y III. En ellos se estudiaba en latín a Cicerón: De oratore (Sobre el orador), De amicitia (Sobre la amistad), De senectute (Sobre la ancianidad) y las Catilinarias, analizadas desde el punto de vista estilístico y oratorio. Se estudiaba a Virgilio - las Bucólicas, las Geórgicas y la Eneida - y a Horacio — los cuatro libros de las Odas, algunas Cartas y el Arte poética-. Recuerdo que en la primera lección sobre Horacio se nos pidió leer para la clase siguiente (unos días después) el primer libro de las Odas (eran nada menos que treinta) y así sucesivamente los otros tres libros. Julio César también estaba muy presente, sobre todo con De bello gallico (La guerra de las Galias). Mientras cada estudiante avanzaba en la lectura y el análisis de las obras, los profesores iban explicando en las clases los adiuncta, es decir, los "contextos" históricos, culturales, políticos y económicos, así como los personajes y los mitos que iban apareciendo en las diversas obras. Un paso ulterior, todavía más exigente, era el estudio de la Prosodia y métrica latina (el arte de combinar las cantidades de cada sílaba, largas o breves) para la confección cadenciosa de los versos y los estudiantes más avanzados eran estimulados a componer versos en latín.

\section{Los autores clásicos griegos}

De manera paralela, pero no con la misma intensidad, se estudiaba griego. En primer lugar, la gramática y se iban añadiendo algunos autores cuya dificultad se dosificaba. Se comenzaba con La llave del griego, obra compuesta por los jesuitas Eusebio Hernández y Félix Restrepo. La obra es una selección y un análisis sintáctico, semántico y etimológico de algunos textos breves de autores clásicos y fragmentos de obras extensas como la Odisea. Se avanzaba con lecturas sencillas, como el capítulo primero del Evangelio de san Lucas, luego se continuaba con algunos textos más complejos como la "Homilía de San Juan Crisóstomo en favor de Eutropio" y poco a poco se llegaba a obras mucho más complejas como el Prometeo encadenado, de Esquilo; el Edipo rey, de Sófocles y las Filípicas, de Demóstenes, quizás el orador más grande de la Antigüedad. Guillermo, que iba tres años adelante en sus estudios, se había distinguido a lo largo de todas estas etapas y fue designado como profesor de Griego de sus compañeros. Fui su discípulo cuando enseñaba la primera Filípica de Demóstenes. Platón (El banquete) y Aristóteles (Ética a Nicómaco y Ética a Eudemo) se reservaban para los estudios posteriores de Filosofía.

\section{La lectura individual y grupal de autores literarios}

Si bien los autores griegos y latinos conformaban el eje central de la formación humanística, los grandes autores de la literatura universal no estaban ausentes. Era obligatoria la lectura individual de El Quijote, de alguna de las obras de Teresa de Jesús y de otros autores del Siglo de Oro español. De cada lectura individual se debía presentar un trabajo analítico y crítico. Había también lecturas en común de autores clásicos como Shakespeare o de algunos contemporáneos como Ibsen (Casa de muñecas), Buero Vallejo (Historia de una escalera), Luigi Pirandello (Seis personajes en busca de autor) y otros. En esas lecturas, todas ellas del género teatral, se indicaba con anterioridad a cada 
estudiante el seguimiento psicológico y caracterológico de un personaje (por ejemplo, de Hamlet, Otelo o Ricardo III), el análisis de su comportamiento ético, la consistencia de la trama, la lógica del clímax y su solución o la belleza literaria de algún pasaje. Luego, a la manera de un cinefórum, se ponían en común y se discutían los informes de cada estudiante. Una clara finalidad que se perseguía era el conocimiento y la comprensión de las pasiones humanas, el desarrollo de la sensibilidad y la toma de conciencia de las actitudes personales ante los dramas y las tragedias de la condición humana.

Por la fuerza de su expresión, el género teatral desempeñaba un papel de gran importancia en el proceso formativo, pero no se reducía a la lectura: se pasaba a la acción. Cada año, para celebrar la Navidad, el final y comienzo del año, los estudiantes debían montar en su totalidad - desde la confección de telones, tramoyas y escenografías, hasta la misma actuación - tres obras escénicas: un drama o una tragedia, una zarzuela y una comedia. Guillermo no era un gran actor, pero sí un gran inspirador; recuerdo, por ejemplo, el entusiasmo intelectual que puso en el montaje del Edipo rey, de Sófocles.

\section{La Historia Universal del Arte}

La Historia del Arte era un complemento indispensable de esa formación humanística. En esta asignatura, desarrollada en dos semestres, se trataba de dar una visión de conjunto del desarrollo del arte en sus diversas manifestaciones: pintura, escultura, arquitectura, música y literatura. Se hacía énfasis en la incidencia que tenían los aspectos sociales, políticos, económicos, religiosos y culturales en el desarrollo de las diversas artes. Era un trabajo interdisciplinario, aunque en ese tiempo no se llamaba así a esta modalidad del conocimiento. La historia procuraba ser omniabarcadora: se partía de las pinturas rupestres, de las primeras manifestaciones artísticas de los pueblos caldeos, fenicios, egipcios, griegos y romanos y se pasaba por el Medioevo y el Renacimiento, hasta llegar a las artes contemporáneas con pintores como Picasso y Dalí, con impresionistas como Monet, Cézanne y Degas, con escultores como Rodin y arquitectos como Le Corbusier y Gaudí.

\section{Las audiciones musicales}

Con menor intensidad y sin obligatoriedad alguna, pero siempre presentes, estaban las audiciones musicales. En los días de fiesta y de vacación, los estudiantes que deseaban acudían a la Sala de Música para aprender a deleitarse con los grandes autores clásicos como Beethoven, Bach, Mozart o Händel o los románticos como Schubert, Wagner, Mahler y Strauss.

\section{Guillermo Hoyos-Vásquez, humanista}

Son muchas las formas de entender el humanismo y también las maneras de aplicar el calificativo de humanista a una persona. No es este el lugar para entrar en una discusión al respecto. Un humanista es, sencillamente, una persona que ha sabido asimilar y vivir de modo integral los grandes valores del ser humano: no solo intelectuales, sino también espirituales, sociales, éticos y estéticos. El compromiso intelectual, social y político de Guillermo Hoyos-Vásquez desde la Filosofía tiene como trasfondo su formación humanística y su profunda sensibilidad por todo lo humano. "Homo sum, humani nihil a me alienum puto" (hombre soy; nada humano me es ajeno), había dicho el autor latino Publio Terencio Africano (165 a. C.) en su comedia El enemigo de sí mismo. Y Miguel de Unamuno, después
Descripción del artículo | Article description | Artigo descrição | Description de l'article

El artículo nos introduce en una narración inédita del trasfondo humanístico que marcó la actividad filosófica, social y educativa de Guillermo Hoyos-Vásquez. Relata la historia formativa que contribuyó a forjar su carácter de auténtico humanista desde el bachillerato hasta los estudios universitarios, por medio de la lectura de clásicos, la Historia del Arte y la música. Evoca la imagen del filósofo y educador en su profunda sensibilidad por todo lo humano y, en particular, por el ser humano concreto y real. 
de citar esta sentencia en la introducción a su obra Del sentimiento trágico de la vida, afirma:

Yo diría más bien, nullum hominem a me alienum puto; soy hombre, a ningún otro hombre estimo extraño. Porque el adjetivo humanus me es tan sospechoso como su sustantivo abstracto humanitas, la humanidad. Ni lo humano ni la humanidad, ni el adjetivo simple ni el sustantivado, sino el sustantivo concreto: el hombre.

Guillermo fue un humanista, porque en su labor filosófica, docente y política se comprometió con el ser humano concreto: con el que sufre, lucha, trabaja, goza y busca realizar el ideal de una sociedad justa, igualitaria y pluralista.

\section{Sobre el autor}

Gerardo Remolina-Vargas es doctor en Filosofía. Profesor emérito de la Facultad de Filosofía, exdecano de la Facultad de Ciencias Sociales, exrector de la Pontificia Universidad Javeriana, exdirector del Doctorado en Ciencias Sociales y Humanas. 